\title{
With the start of a new year, a final editorial for Technology and Disability
}

This is the final editorial for the year 2011 and also the last for me as editor of the journal Technology and Disability. Yes, I give the journal the full title it has had for 20 years now: it was first published in 1991, and by the time you read this it will be 2012 .

The time has come for me to write my last editorial for this remarkable journal, Technology and Disability:

- Introducing the first special issue of 2012, which features "Outcome Research in the field of Assistive Technology".

- A new editor in chief, Gert Jan Gelderblom, has been appointed by the AAATE-board. Bea Diederen will continue to assist the editorial bureau: she remains one of those essential people central to the publication of the journal.

- This is also a time to look back and reflect on the past of Technology and Disability.

\section{This Special Issue}

First let me say something about this special issue of "Outcome Research in the field of Assistive Technology" coordinated by the guest editors, Åse Brandt and Jenny Alwin. I refer to the very excellent guest editorial which summarizes the aims, content and results featured in this special issue, which I value great1y. The guest editorial points out the challenges and requirements for outcome research in our field of assistive technology. There is a need for more and renewed research designs to support the implementation of evidence based practice. It is clear that service delivery does have a major influence on individual outcomes. The recommendation is to define the steps which make up the service delivery process and, where possible, harmonize those steps and processes.
Thank you very much Åse and Jenny. I should like to make one additional comment on how technical researchers, developers and designers can benefit from this type of research.

Technology and Disability has an extremely wide scope, dealing as it does with the ways in which people can be assisted, by means of technology, in participating in our complex and demanding society. Unfortunately, all technologies specially designed for persons with a disability have to be defended, due to the extra costs which they are assumed to incur. Briefly, this is one of the three main reasons that outcome research has become so essential; maybe even the most important research area. The second reason is of course the need to enable practitioners and users to choose the best solution. The third reason is that we must remain critical in our examination of the results and effects on participation, because the best is seldom enough, and outcome research teaches us where further exploration and improvement is needed. In my opinion, outcome research should not just end in a "yes" or "no" as to whether a particular application would represent an effective investment in financial terms. Outcome research should be designed in such a way that it also provides the basis for recommendations leading to further improvement of the assistive technology itself, or for working on alternative solutions. I find that in general, this has scarcely been addressed in the discussion and conclusion chapters of "Outcome" articles. Alternatively, you may argue that this is not the task of the outcome researcher, but rather of the readers - in other words: the AAATE.

\section{A new Editor-in-Chief}

After 12 years of working for the journal, the time has come for a change of editorship. It is not without 
regret that I leave this position, but I realize that once retired, I may soon no longer be sufficiently up-to-date, and that a successor will have new ideas and insights which will be important and beneficial for the journal. It is my great pleasure to introduce Dr. Gert Jan Gelderblom as the new editor of this journal. Gert Jan will introduce himself in the next issue, but I should like to mention here that he has developed an expertise in evaluating the results of assistive technologies: better functioning, more and effective outcomes and, moreover, the methodology of research in this matter. He is very well suited to the role of editor: running the process in collaboration with Bea Diederen, thinking of new special issues, motivating guest editors and authors, safeguarding and improving the quality, achieving more papers and pages, obtaining better citation scores, moving into the area of electronic publishing and maintaining connections with the readers and authors - both the sustainable core of AAATE members and the many non-members worldwide, and more. If you have a natural, inborn motivation for working in technology and disability, it is not very difficult to maintain Technology and Disability, but getting it to grow as described above will be a real challenge for the editor and the AAATE board.

\section{A few words to remind us of the past}

The journal Technology and Disability was started in 1991 by Joseph Lane and Robert Mann. The title has not been changed since then, and may well stay as it is. It demonstrates the connection between people and technology for the benefit of people. Technology can then often become part of a person's identity.

Unlike journals which suffer from a waiting list of submitted papers and have a very impressive schedule of issues per year, our journal has sufficient space, and welcomes the input of appointed guest editors. For the first 8 years it consisted almost solely of special topic issues. When the AAATE took it over from Joe Lane and Robert Mann, we decided also to allow a significant number of free papers: half of the issues for special topics and half for free papers being the intention. It turned out that one-third of the issues have been dedicated to special topics and the rest to free papers. Special issues are initiated by the editor in chief, or requested (and generally accepted) by contributors who have valuable material at hand or see the need to establish a state-ofthe-art in a particular field. The reward to the guest editor in terms of satisfaction is high. During talks
Table 1

\begin{tabular}{|c|c|c|}
\hline Topic & Vol. & Year /Pages \\
\hline [not in archive] & $1-1$ & $1991 / 2$ \\
\hline $\begin{array}{l}\text { Assistive Technology in Secondary and } \\
\text { Higher Education }\end{array}$ & $1-2$ & $\sim 300 \mathrm{pp}$ \\
\hline Credentialling & $1-3$ & \\
\hline The Workplace & $1-4$ & \\
\hline Older Persons & $2-1$ & 1993 \\
\hline International perspectives & $2-2$ & 350pp \\
\hline The Human face of AAC Technology & $2-3$ & \\
\hline Home Modifications & $2-4$ & \\
\hline Deafness and Hearing Impairment & $3-1$ & 1994 \\
\hline Special Education & $3-2$ & $334 \mathrm{pp}$ \\
\hline Telecommunications & $3-3$ & \\
\hline Research and Development & $3-4$ & \\
\hline Rural Technology & $4-1$ & 1995 \\
\hline Research and development Part II & $4-2$ & $342 \mathrm{pp}$ \\
\hline $\begin{array}{l}\text { Assistive Technology and persons with } \\
\text { developmental disabilities }\end{array}$ & $4-3,4$ & \\
\hline Seating and Wheeled Mobility & $5-1$ & 1996 \\
\hline Robotics & $5-2$ & 406pp \\
\hline Tech Act / Outcomes Measurement & $5-3,4$ & \\
\hline Policy and Practice in the 90's & $6-1,2$ & 1997 \\
\hline Vision Impairment & $6-3$ & $225 p p$ \\
\hline $\begin{array}{l}\text { Technology Transfer } \\
\text { free papers }\end{array}$ & $\begin{array}{c}7-1,2 \\
7-3\end{array}$ & $\begin{array}{l}1997 \text { half year } \\
228 \mathrm{pp}\end{array}$ \\
\hline Home Modifications & $8-1,2$ & 1998 \\
\hline The Internet and Disability & $8-3$ & $364 p p$ \\
\hline The Field of Assitive Technology & $9-1,2$ & \\
\hline The role of Consumers in R\&D & $9-3$ & \\
\hline Research and Development in Europe I & $10-1$ & 1999 \\
\hline Research and Development in Europe II & $10-2$ & 198pp \\
\hline Aging & $10-3$ & \\
\hline Occupational Therapists & $11-1,2$ & $1999 / 2000$ half \\
\hline Research and Development in Japan & $11-3$ & year $181 \mathrm{pp}$ \\
\hline
\end{tabular}

with the AAATE board about support for the journal, I suggested a more intense interaction between the editor of T\&D with the AAATE board concerning the topics for special issues. Whether it be an area of problems or challenges, one showing significant progress, or a topic seen in the political context as ready for receiving extra funding etc.. I hope that the board will take this up and, when formulating AAATE-policy, translate it into work for the editors of the journal. With a friendly smile (you know me) I would like to thank the board very much for allowing me to do what I wanted; my thanks for the appreciation from your side, and the few minutes at the AAATE general assembly every two years. But make it challenging for the new editor to cope with ideas from your side; he is worthy of it.

In the following tables you will see the topics, with the guest editors in charge for those topics listed, and the number of pages. It was fun to leaf through the paper material and see, for example, a first paper on the internet to come, or the first special issue on robotics. 
Table 2

\begin{tabular}{|c|c|c|c|}
\hline Guest Editors & Special Issue or Free Paper issue & Vol. & $\begin{array}{l}\text { Year/ } \\
\text { Pages }\end{array}$ \\
\hline & free papers & $12-1$ & 2000 \\
\hline \multirow[t]{5}{*}{ Robert Mann } & Best Papers from "Issues in Graduate Education and Research" & $12-2,3$ & $167 \mathrm{pp}$ \\
\hline & free papers & $13-1,2$ & 2001 \\
\hline & free papers & $13-3$ & $185 \mathrm{pp}$ \\
\hline & free papers & $14-1$ & 2002 \\
\hline & free papers & $14-2$ & $207 \mathrm{pp}$ \\
\hline $\begin{array}{l}\text { Gert Jan Gelderblom, Luc P. de } \\
\text { Witte }\end{array}$ & $\begin{array}{l}\text { The Assessment of Assistive Technology Outcomes, Effects and } \\
\text { Costs }\end{array}$ & $14-3$ & \\
\hline \multirow[t]{2}{*}{ Jane Seale, Alan Turner-Smith } & Bringing AT Professionals Together & $14-4$ & \\
\hline & free papers & $15-1$ & 2003 \\
\hline Peter Kyberd, & Advances in the Control of Prosthetic Arms & $15-2$ & 278pp \\
\hline \multicolumn{4}{|l|}{ Paul Chappell, David Gow } \\
\hline \multirow[t]{4}{*}{ Charles G. Willems } & Smart Homes & $15-3$ & \\
\hline & free papers & $15-4$ & \\
\hline & free papers & $16-1$ & 2004 \\
\hline & free papers & $16-2$ & $243 p p$ \\
\hline \multirow{3}{*}{$\begin{array}{l}\text { Serenella Besio, Anna-Liisa } \\
\text { Salminen }\end{array}$} & Children and Youngsters and Technology & $16-3$ & \\
\hline & free papers & $16-4$ & \\
\hline & free papers & $17-1$ & 2005 \\
\hline \multirow{6}{*}{$\begin{array}{l}\text { Lucas van der Woude, Thomas } \\
\text { Janssen, DirkJan Veeger }\end{array}$} & Restoration of Wheeled Mobility in SCI Rehabilitation & $17-2$ & 256pp \\
\hline & free papers & $17-3$ & \\
\hline & free papers & $17-4$ & \\
\hline & free papers & $18-1$ & 2006 \\
\hline & free papers & $18-2$ & 240pp \\
\hline & free papers & $18-3$ & \\
\hline \multirow{2}{*}{$\begin{array}{l}\text { Christian Berger-Vachon, Daniel } \\
\text { Mestre, Alain Pruski }\end{array}$} & Virtual Reality and Disability & $18-4$ & \\
\hline & free papers & $19-1$ & 2007 \\
\hline \multirow[t]{3}{*}{ Inger Hagen } & Technology in Dementia Care & $19-2,3$ & $228 \mathrm{pp}$ \\
\hline & free papers & $19-4$ & \\
\hline & free papers & $20-1$ & 2008 \\
\hline \multirow[t]{6}{*}{ Klaus Fellbaum } & Electronic speech processing for persons with disabilities & $20-2$ & $301 \mathrm{ppp}$ \\
\hline & free papers & $20-3$ & \\
\hline & free papers & $20-4$ & \\
\hline & free papers & $21-1,2$ & 2009 \\
\hline & free papers & $21-3$ & $173 \mathrm{pp}$ \\
\hline & free papers & $21-4$ & \\
\hline \multirow[t]{2}{*}{ Asim Smailagic } & Quality of Life Technology: Intelligent Systems for Better Living & $22-1,2$ & 2010 \\
\hline & free papers & $22-3$ & $231 \mathrm{pp}$ \\
\hline \multirow[t]{3}{*}{ Richard Foulds, Sergei Adamovich } & State of the Science for Pediatric Rehabilitation Engineering & $22-4$ & \\
\hline & free papers & $23-1$ & 2011 \\
\hline & free papers & $23-2$ & $254 \mathrm{pp}$ \\
\hline \multirow[t]{2}{*}{ Christian Bühler, Jan Engelen } & $\begin{array}{l}\text { Twenty Years of Innovation in the European Assistive Technology } \\
\text { and Inclusion Sector: A Critical Review }\end{array}$ & $23-3$ & \\
\hline & free papers & $23-4$ & \\
\hline \multirow[t]{2}{*}{ Åse Brandt, Jenny Alwin } & Outcome Research within the field of Assistive Technology & $24-1$ & 2012 \\
\hline & & & $-\mathrm{pp}$ \\
\hline
\end{tabular}

The first table shows the list produced by the initiators of Technology and Disability. The second table is from the AAATE period.

\section{Final words}

I am very much aware that without the support of a publisher such as IOS Press, a journal like this cannot be maintained. Those at IOS have always been very helpful, friendly (extremely important), professional and available at conferences and other events to meet our readers and authors. Thanks to Marion Lilley, who is primarily responsible for the journal Technology and Disability, Einar Frederikson (CEO) and his staff.

Reviewers and editors also have a crucial role. Difficult messages to authors are better received when you 


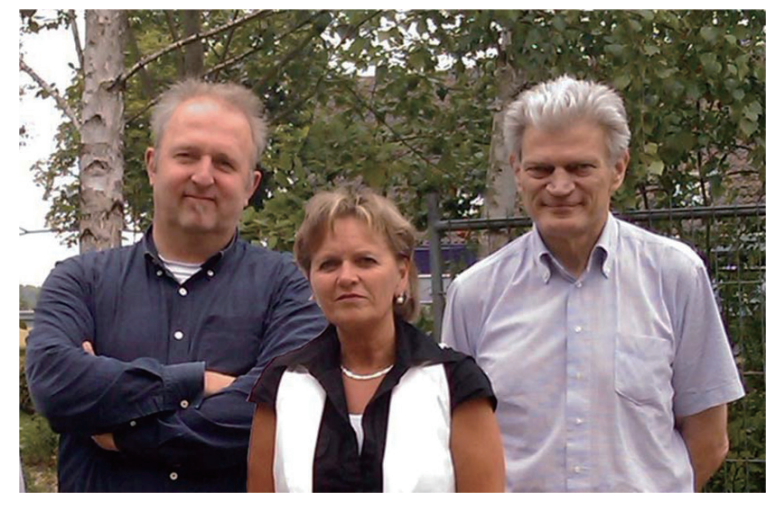

Fig. 1. From left to right, Gert Jan Gelderblom, Bea Diederen and Thijs Soede.

have correctly formulated argumentation from other professionals at your disposal. All in all, they have done an amazing job, and they were often pleased to see such good material submitted for review and to be given the chance to have their advice implemented. It has occasionally been more difficult with papers of lesser quality, but I always took seriously the attempt to set the author on a better track.

Last but not least, who other than Bea Diederen, whose efforts acting as officer for the journal have never failed to get the work done and organized. Bea even managed to get the job done with some of the slowest reviewers. Bea, I hope that you will continue to derive the same satisfaction from this work as ever, and that the planned introduction of the electronic review system will make your life a bit easier.

Good luck GertJan, Bea, Marion, Einar, Reviewers, Authors, AAATE board members, colleagues in Assistive Technology work.

I wish you all a very prosperous, happy and productive year 2012,

Thijs Soede Editor-in-Chief-now retired! 